\section{Antimicrobial resistance of Klebsiella pneumoniae strains isolated from urine in hospital patients and outpatients}

\section{Maja Ostojic ${ }^{1}$, Mahir Hubana ${ }^{2}$, Marija Cvetnić ${ }^{3}$, Miroslav Benić ${ }^{4}$ and Zeljko Cvetnić2*}

'Department of Microbiology and Molecular Diagnostics, University Clinical Hospital Mostar, Bosnia and Herzegovina

${ }^{2}$ Faculty of Pharmacy, University of Mostar, Bosnia and Herzegovina

${ }^{3}$ Faculty of Veterinary Medicine, University of Zagreb, Croatia

${ }^{4}$ Croatian Veterinary Institute, Croatia

\section{Abstract}

Background: Klebsiella pneumoniae is a bacterial species that often causes infections in humans. Infections occur most frequently in hospitalised or immunocompromised patients and are treated with antimicrobials. In recent decades, $K$. pneumoniae has developed significant resistance to many antimicrobials.

Objective: The main goal of this study was to determine the frequency of resistance of isolated K. pneumoniae strains from urine samples of hospital patients and outpatients, and to find evidence of ESBL strains and their resistance to certain antibiotics.

Methods: During the study period, Klebsiella pneumonia was isolated from the urine samples of 430 patients. The procedure for processing of urine samples, identification, susceptibility toward antimicrobials and evidence of ESBL strains were carried out according to the recommended standards.

Results: Of the total K. pneumoniae isolates, $153(35.6 \%)$ were isolated from hospital patients and $277(64.4 \%)$ from outpatients. Strains isolated from hospital patients were resistant to each tested antibiotic. ESBL strains were detected in 169 (39.30\%) samples, 92 (60.13\%) from hospital patients and $77(27.8 \%)$ from outpatients.

Conclusion: Strains of $K$. pneumoniae isolated from the urine of hospital patients and outpatients have developed significant resistance against all tested antibiotic substances. A higher occurrence of ESBL strains was observed in hospital patients than in outpatients. ESBL strains were resistant to all penicillins and almost all cephalosporins. Highly effective antimicrobials were amikacin, colistine, carbapenem and fosfomycin. The best therapeutic results were achieved when patients were treated with fosfomycin and imipenem.

\section{More Information}

*Address for Correspondence: Željko Cvetnić, DVM, PhD, Professor of Microbiology, Matice Hrvatske BB, 88000 Mostar, Bosnia and Herzegovina, Tel: ++387 36312 791; Fax: ++387 36312 791; Email: cvetnic@veinst.hr

Submitted: February 13, 2021

Approved: February 25, 2021

Published: February 26, 2021

How to cite this article: Ostojic M, Hubana M Cvetnić M, Benić M, Cvetnić Z. Antimicrobial resistance of Klebsiella pneumoniae strains isolated from urine in hospital patients and outpatients. Arch Biotechnol Biomed. 2021; 5: 001-007.

DOI: 10.29328/journal.abb.1001021

Copyright: ( 2021 Ostojic M, et al. This is an open access article distributed under the Creative Commons Attribution License, which permits unrestricted use, distribution, and reproduction in any medium, provided the original work is properly cited.

Keywords: Klebsiella pneumonia; Antibiotic resistance; ESBL strain; Hospital patients; Outpatients

W) Check for updates

OPEN ACCESS

\section{Introduction}

Klebsiella (K.) pneumoniae is a species that often causes infections in humans. As a primary pathogen, it most commonly causes pneumonia and urinary tract infection [1]. The bacterium lives as a commensal mainly in the digestive system of humans and animals, but is also widespread in the environment. Infections occur most frequently in hospitalised or immunocompromised patients, and are routinely treated with $\beta$ lactam antibiotics and other antibiotics against enterobacteria [2]. Due to its rapid spread, Klebsiella infection is the third most common hospital infection in the United States (9.9\%), after Clostridium difficile and Staphylococcus aureus. K. pneumoniae causes serious infections including pneumonia, urinary tract and circulatory infections [3]. Outbreaks of Klebsiella infections are often caused by newly emerged resistant strains with expanded spectrum beta lactamase production (ESBL) [4], and their frequency has been increasing for years. The increasing trend of the occurrence 
of Klebsiella infection is particularly pronounced in Eastern Europe [5]. The environment is an important source and reservoir of K. pneumonia, and it is frequently isolated from water, sewage, soil and plant surfaces. In a study of surface water samples, 123 Klebsiella strains were isolated from $53 \%$ of samples with K. pneumoniae as the dominant species [6]. Recent studies have also shown that highly pathogenic $K$. pneumonia strains, containing resistance and virulence genes similar to those detected in human strains, are often found in pets such as dogs and cats. High similarity has been demonstrated between strains isolated from pets and humans with urinary infection and highly pathogenic clones of K. pneumoniae (> 86.7\%). Hence, owners and pet handlers must be cautious to prevent the spreading of infection [7].

One of the most common modes of transmission of K. pneumoniae in the hospital environment is direct contact between healthcare professionals and patients. Contaminated surfaces of instruments have also been detected as sources of infection [8]. Transmission of K. pneumoniae in the community is considered to be lower than in hospitals. The colonisation of the nasopharynx is higher in adults than in children (15\% vs. $7 \%$ ). The main means of transmission is poor food and water hygiene [9]. The gastrointestinal system is a significant reservoir of K. pneumoniae and source of infection, since it is often colonised [10]. Urinary tract infections are among the most common human infections and represent an important public health problem with high economic implications. Due to the widespread use of antibiotics to treat urinary infections, antibacterial resistance of Enterobacteriaceae, in particular the major uropathogens Escherichia coli and K. pneumoniae, has increased significantly worldwide. The increased prevalence of resistance of Enterobacteriaceae toward the most commonly used antibiotics limits the availability of treatment for infections caused by these bacteria [11]. Klebsiella producing ESBL are resistant to many antibiotics, including aminoglycosides, fluoroquinolone, tetracyclines, chloramphenicol, trimethoprim + sulfametoxazole, penicillins and cephalosporins [12]. Infections caused by ESBL strains can only be treated by carbapenem, such as imipenem, meropenem, ertapenem and others [13], though carbapenems should be avoided whenever possible, as the last line of defence in case of infection with a highly resistant strain if no other effective antibiotic against infection is available. Such cases have been reported in India, Europe and across the world [14].

The main goal of this study was to determine the resistance pattern of $K$. pneumoniae isolates from hospital patients and outpatients, to determine the extent of resistance and sensitivity of K. pneumonia among isolates, and to determine associations of resistance patterns with patient gender and age. Finally, the aim was to express the proportion of resistant ESBL strains of $K$. pneumoniae in hospital patients and outpatients.

\section{Materials and methods}

The study was carried out from January to December 2018 at the Institute of Microbiology and Molecular Diagnosis of Mostar University Clinical Hospital (Bosnia and Herzegovina). Hospital patients were admitted to the Mostar University Clinical Hospital and samples were taken during their stay. Urine samples from outpatients were delivered to the Institute of Microbiology and Molecular Diagnosis, Mostar University Clinical Hospital based on a physician's instructions from primary health care.

A total of 430 K. pneumoniae strains isolated from urine samples were analysed. During the study period, 153 strains were isolated from hospital patients and 277 from outpatients.

\section{Isolation and identification of isolated bacteria}

To sample urine, $10 \mathrm{~mL}$ of the middle stream was taken. In exceptional circumstances urine was taken by catheter in hospitalised patients. Urine samples were inoculated on nonselective ( $5 \%$ blood agar) and selective McConkey agar (Oxoid, UK) and incubated for 24 hours in a thermostat at $37^{\circ} \mathrm{C}$. Gram negative bacteria were identified by standard microbiological methods.

Phenotypic and biochemical properties of grown colonies were evaluated in order to identify Klebsiella. The colonies were cultivated on McConkey agar and blood agar. The colonies on McConkey agar were up to $3 \mathrm{~mm}$ in diameter, mucous and lactose positive. Colonies on blood agar appeared as grey coloured, shiny colonies up to $3 \mathrm{~mm}$ in diameter. Commercially available substrates (Oxoid, UK) were used to avaluate biochemical properties of suspected Klebsiella colonies such as Kligler agar (containing two sugars), SIM medium (sulphide, indole, motility) and citrate agar. After 24 hours incubation at $37{ }^{\circ} \mathrm{C}$ Klebsiella ferments both glucose and lactose producing gas during the growth. Bacterium is non-motile, does not produce $\mathrm{H}_{2} \mathrm{~S}$, it is indole negative and ferments citrate. The final identification was carried out using the automated closed system for the identification and testing of susceptibility VITEK 2 Compact (BioMérieux, France) according to the manufacturer's instructions[1,15].

After the identification, isolates were submitted to the susceptibility test toward antimicrobials using Kirby Bauer disc diffusion method. Five colonies of a freshly cultured bacterial strain (overnight culture) were picked up using inoculation loop and diluted in $2 \mathrm{ml}$ of sterile saline. Suspension was vortexed in order to create a smooth suspension and turbidity was adjusted to a 0.5 according to McFarland. Suspension was inoculated on surface of Miller Hinton agar within 15 minutes after preparation with a sterile cotton swab dipped into inoculum tube. Excess fluid was removed by rotating the swab against the side of the tube (above the fluid level) using firm pressure. The surface of a $\mathrm{MH}$ agar plate was inoculated by streaking the swab three times over the entire agar surface; 
rotating the plate approximately 60 degrees each time to ensure an even distribution of the inoculum. Inoculated plate was left several minutes to dry. Disks were applied firmly on the agar surface within $15 \mathrm{~min}$ of inoculation of the plates. Within $15 \mathrm{~min}$ of application of antimicrobial disks, the plates were inverted and incubated at $35 \pm 1{ }^{\circ} \mathrm{C}$ for $16-20 \mathrm{~h}$. After incubation, inhibition zones were read at the point where no obvious growth was detected by the unaided eye when the plate is held about $30 \mathrm{~cm}$ from the eye. The inhibition zone diameters are measured to the nearest millimetre with a ruler. The procedure is standardized and the results are interpreted according to EUCAST [16]. We tested bacterial isolates for the following substances: amikacin (AKN) $30 \mu \mathrm{g}$ amoxicillin (AMX) $25 \mu \mathrm{g}$, amoxicillin + clavulanic acid (AMC) 20/10 $\mu \mathrm{g}$, ampicillin + sulbactam (SAM) 10/10 $\mu \mathrm{g}$, ceftazidim (CZD) $10 \mu \mathrm{g}$, ceftriaxone (CRO) $30 \mu \mathrm{g}$, cefuroxime (CXM) $30 \mu \mathrm{g}$, cefazolin (CZN) $30 \mu \mathrm{g}$, cefoperazone (CPZ) $30 \mu \mathrm{g}$, cefotaxime (CTX) $30 \mu \mathrm{g}$, ciprofloxacin (CIP) $5 \mu \mathrm{g}$, fosfomycin (FSF) $50 \mu \mathrm{g}$, gentamicin (GMN) $10 \mu \mathrm{g}$, levofloxacin LVX) $5 \mu \mathrm{g}$, nitrofurantoin (NFE) $100 \mu \mathrm{g}$, pefloxacin (PEF) $5 \mu \mathrm{g}$, piperacillin (PIL) 30 $\mu \mathrm{g}$, trimethoprim + sulfamethoxazole (SXT) 1.25/23.75 $\mu \mathrm{g}$, ertapenem ETP) $10 \mu \mathrm{g}$, meropenem (MEM) $10 \mu \mathrm{g}$, imipenem (IPM)10 $\mu \mathrm{g}$, colistin (COL) $10 \mu \mathrm{g}$ (Bio Rad, France).

\section{Testing of bacterial strains $K$. pneumoniae for ESBL production}

The production of ESLB was determined by the double disc synergy test (DDST) method. Screening and confirmatory tests for detection of ESBL strains were performed according to valid standards (Clinical and Laboratory Standard Institute) and EUCAST [17-19]. Discs containing ceftazimidin (CAZ 30), amoxicillin + clavulanic acid (AMC10/10) and ceftriaxone (CRO30) were placed on the surface of Mueller Hinton's agar inoculated with bacterial suspension of proper density $(0.5$ according to McFarland). The distance between the centres of discs was $20 \mathrm{~mm}$. Plates were incubated at $37{ }^{\circ} \mathrm{C}$ for 18-24 hours. After incubation, synergism between discs was evaluated. The smallest sign of synergism between discs was considered a positive test result, i.e., the strain had the ability to produce expanded spectrum $ß$ lactamase (ESBL).

\section{Statistical analysis}

The IBS SPSS Statistics for Mac OSX statistical package (version 23, SPSS Inc, Chicago, Illinois, USA) was used for data analysis.

The Chi-square test $\left(\chi^{2}\right)$ was used to compare the differences of infection occurrence between hospital patients and outpatients by gender. The Chi-square $\left(\chi^{2}\right)$ and Fisher exact tests were used to compare the differences of bacterial susceptibility against antimicrobials isolated from hospital patients and outpatients. Student's $t$ - test was used to compare age differences between hospital patients and outpatients. Probability less than 0.05 was considered statistically significant.

\section{Results}

Of the total number of patients with K. pneumonia urinary infection, 153 (35.6\%) were hospitalised while 277 (64.4\%) were outpatients, and this difference was statistically significant $\left(\chi^{2}=35.75 ; \mathrm{df}=1 ; p<0.05\right)$.

Infection was more frequently confirmed in female $(244 \%$ or $56.74 \%$ ) than male patients (186\% or $43.26 \%)$. Assuming that infection occurs with the same frequency in both sexes, the observed difference in the distribution by gender was statistically significant $\left(\chi^{2}=7.82 ; \mathrm{df}=1 ; p<0.05\right)$.

The age of patients ranged from 15 to 95 years, with a mean age of 66.14 years ( $S D=18.07)$. The mean age of male patients was 69.02 years $(S D=15.87)$ and female of 63.93 years $(S D=$ 19.33), and the observed difference in patient age by gender was statistically significant $(t=2.992 ; \mathrm{df}=424.4 ; p=0.003)$.

Analysis of the susceptibility pattern of $K$. pneumoniae isolated from hospital and non-hospital patients showed that strains isolated from hospital patients were more resistant to each of the tested antibiotic, with the exception of fosfomycin (Table 1).

Of the 430 analysed isolates of $K$. pneumoniae, ESBL production was detected in 169 (39.30\%) analysed strains. Of the ESBL positive strains, 92 (60.13\%) came from hospital patients (of the 153 analysed), and 77 (27.8\%) originated from outpatients. Strains able to synthesise ESBL were detected in $111(66.07 \%)$ males and 58 (34.53\%) females. The observed difference of the distribution of ESBL strains between genders was statistically significant. Male patients were in more frequently infected with strains able to produce ESBL $\left(\chi^{2}=\right.$ 16.095; $\mathrm{DF}=1 ; p<0.05$ ).

Table 2 shows the sensitivity of ESBL producing strains toward different antibiotics in the two patient groups.

\section{Discussion}

Urinary tract infections are among the most common of all bacterial infections and are often a reason for visiting health institutions. Most of these infections are treated in primary health care facilities. However, resistance to antimicrobials used to treat urinary infections is on the rise [20], and the number of hospitalised patients increases with the increase of antimicrobial resistance. In recent decades, hospital treatments of urinary tract infections have increased dramatically, and resistance to standard antibiotics has become very common [21].

In this study, the resistance pattern of $K$. pneumoniae isolated from hospital patients and outpatients with urinary infection to certain antibiotics is presented. These data primarily provide insight into the possibility of successful treatment of these infections. Resistance to penicillin is very widespread, therefore penicillin cannot be considered 
Table 1: Frequency of resistance and sensitivity of isolated strains $K$. pneumoniae from hospital patients and outpatients to certain antibiotics

\begin{tabular}{|c|c|c|c|c|c|c|c|}
\hline \multirow{2}{*}{ Antibiotic } & \multirow{2}{*}{ Designation } & \multirow{2}{*}{$\begin{array}{l}\mathbf{N} \\
\%\end{array}$} & \multicolumn{2}{|c|}{ Hospital patients } & \multicolumn{2}{|c|}{ Outside hospital patients } & \multirow{2}{*}{$p$} \\
\hline & & & Resistant & Sensitive & Resistant & Sensitive & \\
\hline \multirow{2}{*}{ Amikacin } & \multirow{2}{*}{$\begin{array}{l}\text { AKN } \\
30 \mu g\end{array}$} & $\mathrm{~N}$ & 4 & 82 & 3 & 71 & \multirow{2}{*}{$>0.05$} \\
\hline & & $\%$ & 4.65 & 95.35 & 4.05 & 95.95 & \\
\hline \multirow{2}{*}{ Amoxicillin } & \multirow{2}{*}{$\begin{array}{l}\text { AMX } \\
25 \mu g\end{array}$} & $\mathrm{~N}$ & 101 & 0 & 171 & 7 & \multirow{2}{*}{$>0.05$} \\
\hline & & $\%$ & 100 & 0 & 96.07 & 3.93 & \\
\hline \multirow{2}{*}{$\begin{array}{l}\text { Amoxicillin+ } \\
\text { clavulanic acid }\end{array}$} & \multirow{2}{*}{$\begin{array}{c}\text { AMC } \\
20 / 10 \mu \mathrm{g}\end{array}$} & $\mathrm{N}$ & 57 & 28 & 85 & 106 & \multirow{2}{*}{0.0005} \\
\hline & & $\%$ & 67.06 & 32.94 & 44.50 & 55.50 & \\
\hline \multirow{2}{*}{$\begin{array}{l}\text { Ampicillin+ } \\
\text { sulbactam }\end{array}$} & \multirow{2}{*}{$\begin{array}{c}\text { SAM } \\
10 / 10 \mu g\end{array}$} & $\mathrm{~N}$ & 60 & 2 & 62 & 8 & \multirow{2}{*}{$>0.05$} \\
\hline & & $\%$ & 96.77 & 3.23 & 88.57 & 11.43 & \\
\hline \multirow{2}{*}{ Ceftazidim } & \multirow{2}{*}{$\begin{array}{l}\text { CZD } \\
10 \mu g\end{array}$} & $\mathrm{~N}$ & 72 & 39 & 61 & 147 & \multirow{2}{*}{$<0.0001$} \\
\hline & & $\%$ & 64.86 & 35.14 & 29.33 & 70.67 & \\
\hline \multirow{2}{*}{ Ceftriaxone } & \multirow{2}{*}{$\begin{array}{l}\text { CRO } \\
30 \mu g\end{array}$} & $\mathrm{~N}$ & 74 & 42 & 64 & 152 & \\
\hline & & $\%$ & 63.79 & 36.21 & 29.63 & 70.37 & $<0.0001$ \\
\hline & CXM & $\mathrm{N}$ & 91 & 54 & 80 & 168 & \\
\hline Cefuroxıme & $30 \mu \mathrm{g}$ & $\%$ & 62.76 & 37.24 & 32.26 & 67.74 & $<0.0001$ \\
\hline Cefazolin & $\mathrm{CZN}$ & $N$ & 16 & 7 & 14 & 21 & (1) 02751 \\
\hline Cetazolın & $30 \mu \mathrm{g}$ & $\%$ & 69.57 & 30.43 & 40 & 60 & 0.02151 \\
\hline Cefonerazone & $\mathrm{CPZ}$ & $\mathrm{N}$ & 18 & 19 & 11 & 45 & 00031 \\
\hline Ceroperazone & $30 \mu \mathrm{g}$ & $\%$ & 48.65 & 51.35 & 19.64 & 80.36 & 0.0031 \\
\hline Cofotoximo & CTX & $N$ & 18 & 20 & 13 & 51 & Pחת \\
\hline Cefotaxıme & $30 \mu \mathrm{g}$ & $\%$ & 47.37 & 52.63 & 20.31 & 79.69 & 0.004 \\
\hline Cinrofloxacin & CIP & $\mathrm{N}$ & 58 & 50 & 69 & 132 & 0.0009 \\
\hline Ciprofloxacin & $5 \mu \mathrm{g}$ & $\%$ & 53.70 & 46.30 & 34.33 & 65.67 & \\
\hline & FSF & $N$ & 0 & 54 & 2 & 86 & \\
\hline Fostomycin & $50 \mu \mathrm{g}$ & $\%$ & 0 & 100 & 2.27 & 97.72 & $>0.05$ \\
\hline & GMN & $N$ & 57 & 44 & 63 & 140 & \\
\hline Gentamıcın & $10 \mu g$ & $\%$ & 56.44 & 43.56 & 31.03 & 68.97 & $<0.0001$ \\
\hline & LVX & $\mathrm{N}$ & 7 & 9 & 2 & 14 & \\
\hline Levofloxacın & $5 \mu \mathrm{g}$ & $\%$ & 43.75 & 56.25 & 12.50 & 87.50 & $>0.05$ \\
\hline Nitrofurantoin & NFE & $\mathrm{N}$ & 49 & 88 & 80 & 178 & $>005$ \\
\hline Nitroturantoin & $100 \mu \mathrm{g}$ & $\%$ & 35.77 & 64.23 & 31.01 & 68.99 & $>0.05$ \\
\hline Pefloxacin & PEF & $\mathrm{N}$ & 8 & 15 & 14 & 29 & $>005$ \\
\hline Penloxacin & $5 \mu \mathrm{g}$ & $\%$ & 34.78 & 65.22 & 32.66 & 67.44 & $>0.05$ \\
\hline Pineracillin & $\mathrm{PIL}$ & $\mathrm{N}$ & 71 & 0 & 69 & 1 & $>0.05$ \\
\hline Piperacillin & $30 \mu \mathrm{g}$ & $\%$ & 100 & 0 & 98.57 & 1.43 & $>0.05$ \\
\hline Trimethoprim+ & SXT 1 25/23.75ud & $\mathrm{N}$ & 45 & 66 & 63 & 178 & 0006 \\
\hline sulfamethoxazole & $S X \mid 1.25 / 23.15 \mu \mathrm{g}$ & $\%$ & 40.54 & 59.46 & 26.14 & 73.86 & 0.006 \\
\hline & ETP & $\mathrm{N}$ & 6 & 81 & 1 & 71 & \\
\hline Ertapenem & $10 \mu \mathrm{g}$ & $\%$ & 6.9 & 93.1 & 1.39 & 98.61 & $>0.05$ \\
\hline & MEM & $\mathrm{N}$ & 2 & 75 & 1 & 73 & $>005$ \\
\hline Meropenem & $10 \mu \mathrm{g}$ & $\%$ & 2.60 & 97.40 & 1.35 & 98.65 & $>0.05$ \\
\hline Iminenem & IPM & $\mathrm{N}$ & 2 & 69 & 0 & 62 & $>005$ \\
\hline Imıpenem & $10 \mu \mathrm{g}$ & $\%$ & 2.82 & 97.18 & 0 & 100 & $>0.05$ \\
\hline Colistin & $\mathrm{COL} 10 \mu \mathrm{g}$ & $N$ & 3 & 68 & 1 & 57 & $>0.05$ \\
\hline
\end{tabular}

a reliable antibiotic in combatting infections caused by K. pneumoniae. Acceptable results were achieved using cephalosporins, fluoroquinolones or gentamicin, a satisfactory therapeutic effect was achieved with nitrofurantoin and trimethoprim + sulfomethoxazole. The best therapeutic success was expected with carbapenems and colistine as the last line defence antibiotics, and with amikacin and fosfomycin. Fosfomycin was particularly successful, since only 2 of 142 isolates expressed resistance toward it, and its efficacy was equal to imipenem and better than ertapenem and meropenem. A study conducted in the USA from 1998 to 2010 showed a constant trend of increased resistance of $K$. pneumoniae against antibiotics. Resistance against sulfametoxazole + trimethoprim reached $10.9 \%$ in 1998 and increased to $19.3 \%$ in 2010 , while in the same period, resistance to ciprofloxacin increased from $5.5 \%$ to $16.8 \%$. Our study showed $40.5 \%$ resistant $K$. pneumonia isolates against sulfametoxazole + trimethoprim from hospital patients and $26.4 \%$ from outpatients, while resistance to ciprofloxacin was $53.7 \%$ in isolates from hospitalised patients and $34.3 \%$ from outpatients. The resistance in the broader region is even more pronounced due to the inappropriate and uncontrolled use of antibiotics. Resistance against amikacin increased from $0.7 \%$ to $4.5 \%$ in the US study, while in this study it reached 4.6\%. Resistance toward imipenem was not detected in the US at the beginning of the study (1998) but eventually reached $4.3 \%$ [22]. In this study, the resistance of isolates from hospital patients to imipenem was $2.8 \%$. These findings 
Table 2: Susceptibility of ESBL strains $K$. pneumoniae to certain antibiotics in hospital patients and outpatients.

\begin{tabular}{|c|c|c|c|c|c|c|}
\hline \multirow{3}{*}{ Antibiotic } & \multicolumn{3}{|c|}{ Hospital ESBL strains } & \multicolumn{3}{|c|}{ Outside hospital ESBL strains } \\
\hline & \multirow{2}{*}{$\mathbf{N}$} & \multicolumn{2}{|c|}{ Sensitivity ESBL strains } & \multirow[b]{2}{*}{$\mathbf{N}$} & \multicolumn{2}{|c|}{ Sensitivity ESBL strains } \\
\hline & & Number & $\%$ & & Number & $\%$ \\
\hline Amikacin & 88 & 84 & $95.46 \%$ & 70 & 67 & $95.71 \%$ \\
\hline Amoxicillin & 80 & 0 & $0 \%$ & 71 & 0 & $0 \%$ \\
\hline Amoxicillin + clavulanic acid & 71 & 1 & $1.41 \%$ & 68 & 0 & $0 \%$ \\
\hline Ampicillin + sulbactam & 80 & 0 & $0 \%$ & 69 & 3 & 4. $35 \%$ \\
\hline Ceftazidim & 76 & 1 & $1.32 \%$ & 61 & 1 & $1.64 \%$ \\
\hline Ceftriaxone & 78 & 1 & $1.28 \%$ & 66 & 1 & $1.52 \%$ \\
\hline Cefuroxime & 70 & 0 & $0 \%$ & 58 & 0 & $0 \%$ \\
\hline Cefazolin & 76 & 5 & $6.57 \%$ & 64 & 6 & $10.61 \%$ \\
\hline Cefoperazone & 73 & 0 & $0 \%$ & 68 & 0 & $0 \%$ \\
\hline Cefotaxime & 74 & 0 & $0 \%$ & 64 & 0 & $0 \%$ \\
\hline Ciprofloxacin & 75 & 20 & $26.67 \%$ & 69 & 9 & $13.04 \%$ \\
\hline Fosfomycin & 77 & 77 & $100 \%$ & 69 & 67 & $97.10 \%$ \\
\hline Gentamicin & 81 & 12 & $14.8 \%$ & 66 & 8 & $12.12 \%$ \\
\hline Piperacillin & 83 & 0 & $0 \%$ & 61 & 0 & $0 \%$ \\
\hline Nitrofurantoin & 69 & 34 & $49.28 \%$ & 68 & 36 & $52.94 \%$ \\
\hline Pefloxacin & 79 & 20 & $25.3 \%$ & 68 & 19 & $27.94 \%$ \\
\hline Trimethoprim + sulfamethoxazole & 78 & 32 & $41.03 \%$ & 71 & 25 & $35.21 \%$ \\
\hline Ertapenem & 80 & 74 & $92.50 \%$ & 76 & 75 & $98.68 \%$ \\
\hline Imipenem & 87 & 85 & $97.7 \%$ & 73 & 68 & $93.15 \%$ \\
\hline Meropenem & 86 & 84 & $97.67 \%$ & 75 & 74 & $98.67 \%$ \\
\hline Colistin & 82 & 78 & $95.12 \%$ & 73 & 68 & $93.15 \%$ \\
\hline
\end{tabular}

confirm that new strains have appeared. These strains are also resistant against carbapenem (CRKPA) and could pose a serious problem in the future. In 2000 , less than $1 \%$ of K. pneumoniae isolates were resistant to carbapenem, while in 2007 this grew to $8 \%$ [22,23]. A study in Bangladesh showed a $100 \%$ resistance rate of $K$. pneumonia against ampicillin, $90 \%$ against amoxicillin, $45 \%$ against ceftriaxone, $40 \%$ against ciprofloxacin, 25\% against gentamicin and 35\% against tetracycline. The findings of that study are much closer to the results presented here, and far from desirable values [24].

Strains secreting ß-lactamase expanded spectrum (ESBL) appeared for the first time in Germany in the 1980s, and have since spread worldwide, posing a major problem. ESBL production was detected in gram-negative rod-shaped bacteria, with the majority detected in the Enterobacteriaceae family [25]. Prevalence of infection caused by ESBL strains is most common among $K$. pneumoniae isolates in the hospital environment, reaching about $25 \%$, although in some studies this varied from $30 \%$ to $80 \%[25,26]$. In this study, ESBL strains of $K$. pneumoniae were detected in 169 (39.3\%) patients, with 92 isolates $(60.13 \%)$ isolated from hospital patients and 77 isolates $(27.8 \%)$ originated from outpatients. According to the literature, the rate of strains able to produce ESBL in Europe varies from less than $5 \%$ in Scandinavian countries and the Netherlands, to more than $50 \%$ in Greece and Poland. The ability of $K$. pneumoniae strains isolated in Croatia to produce ESBL depends on the origin and reaches about 56\% among invasive isolates and 34\% among clinical isolates, with significant variations among health institutions [27]. The frequency of ESBL producing bacteria may vary within a geographical area or even within a country. The frequency of findings in some earlier surveys was $34 \%$ in Portugal, $37 \%$ in Italy, $44 \%$ in the USA, 30\% - 60\% in Latin American countries and 58\% in Turkey [28]. The choice of antibiotics is particularly important in seriously affected patients with infections caused by ESBL producing K. pneumoniae. This study has confirmed that penicillins and cephalosporins are unsuccessful in the treatment of infection caused by ESBL strains and that fluoroquinolones can cure less than $30 \%$ of patients. Nitrofurantoin is effective in approximately $50 \%$ of patients. Good results, with a success rate of over $95 \%$, were observed in treatment with carbapenem, colistin, amicacin and fosfomycin. Administration of cabazenem, primarily imipenem, prevented mortality from infection with ESBL strains compared with the use of other antibiotics [29]. The therapeutic efficacy of carbapenem has been confirmed in India, the United States, Israel, Greece, and in many European countries, including Croatia. Almost all alternative antibiotics are inefficient against infections with ESBL producing K. pneumonia. Resistance is observed even against antimicrobials still under development. Hence, there is a growing awareness about the possible inability to cure life-threatening infections caused by carbonate-insensitive strains in the future [30,31]. The highest frequency of ESBL strains in relation to patient age was determined in the age group above 65 years. Regarding gender, the affection rate of the pathogen and the body site from which the isolates originated, our findings are in accordance with similar studies, confirming females as the more frequently infected gender and the urinary tract as a commonly affected body system $[32,33]$.

Based on these results, it can be concluded that the 
frequency of infection with isolated $K$. pneumoniae species was determined in $35.6 \%$ of hospital patients and in $64.4 \%$ of outpatients. The infection occurs more frequently in female patients and in patients over 65 years of age. K. pneumoniae developed significant resistance against each tested antibiotic, except fosfomycin, carbapenem, amikacin and choline. The efficacy of cephalosporins, fluoroquinolone, aminoglycosides and trimethoprima + sulfametaxel was satisfactory, and the most effective medicines to be kept for difficult situations in the treatment of infections are carbapenems, amicacin, colistine and fosfomycin. There was a high occurrence of ESBL strains (39.35 cases), which was more common in hospitalised (60.13\%) than in non-hospitalised patients (27.8\%). ESBL strains are resistant against all penicillins and almost all cephalosporins, even against third-generation cephalosporin and in less than $2 \%$ of cases lead to a cure. In less than half of cases, infections can be cured using fluoroquinolones, gentamicin and trimethoprim + sulfometoxazole. Nitrofurantoin was effective in approximately $50 \%$ of cases. Amicacin, colistine, carbapenem and fosfomycin were highly effective, while the best results were achieved when fosfomycin and imipenem were used to treat infection.

\section{References}

1. Kalenić S. Medical Microbiology. Enterobacteriaceae. Medicinska naklada. 2013; 182-197.

2. Martin MM, Bachman MA. Colonization, Infection, and the Accessory Genome of Klebsiella pneumoniae. Front Cell Infect Microbiol. 2018; PubMed: https://pubmed.ncbi.nlm.nih.gov/29404282/

3. Magill SS, Edwards JR, Bamberg W, Beldavs ZG, Dumyati G, et al. Multistate point-prevalence survey of health care-associated infections. N Engl J Med. 2014: 370: 1198-1208.

PubMed: https://pubmed.ncbi.nlm.nih.gov/24670166/

4. Paterson DL. Resistence in Gram-negative bacteria. Enterobacteriaceae. 2006. Am J Med. 119; S8-S20.

PubMed: https://pubmed.ncbi.nlm.nih.gov/16735147/

5. Sekowska A, Janicka G, Klyszejko C. Wojda M, Wroblewski M, et al. Rezistence of Klebsiella pneumoniae strains producing and not producing ESLB (extended spectrum beta lactamase) type enzymes to selected non-beta-lactam antibiotics. Med Sci Mon. 2002; 3: 100-104. PubMed: https://pubmed.ncbi.nlm.nih.gov/11889457/

6. Podschun R, Pietsch S, Höller C, Ullmann U. Incidence of Klebsiella species in surface waters and their expression of virulence factors. Appl Environ Microbiol. 2001; 67: 3325-3327.

PubMed: https://pubmed.ncbi.nlm.nih.gov/11425763/

7. Marques C, Menezes J, Belas A, Aboim C, Cavaco-Silva P, et al Klebsiella pneumoniae causing urinary tract infections in companion animals and humans: population structure, antimicrobial resistance and virulence genes. J Antimicrob Chemother. 2019; 74: 594-602. PubMed: https://pubmed.ncbi.nlm.nih.gov/30535393/

8. Jarvis WR, Munn VP, Highsmith AK, Culver DH, Hughes JM. The epidemiology of nosocomial infections caused by Klebsiella pneumoniae. Infect Control. 1985; 6: 68-74.

PubMed: https://pubmed.ncbi.nlm.nih.gov/3882593/

9. Farida $H$, Severin JA, Gasem $M H$, Keuter $M$, van den Broek $P$, et al. Nasopharyngeal carriage of Klebsiella pneumoniae and other gram-negative Bacilli in pneumonia-prone age groups in Semarang, Indonesia. J Clin Microbiol. 2013; 51: 1614-1616.

PubMed: https://pubmed.ncbi.nlm.nih.gov/23486716/
10. Dorman MJ. Short FL. Klebsiella pneumoniae: when a colonizer turns bad. Nat Rev Microbiol. 2017; 15: 384

PubMed: https://pubmed.ncbi.nlm.nih.gov/28579608/

11. Mazzariol A, Bazaj A, Cornaglia G. Multi-drug-resistant Gram-negative bacteria causing urinary tract infections: a review. J Chemother. 2017; 29: 2-9.

PubMed: https://pubmed.ncbi.nlm.nih.gov/29271736/

12. Falagas ME, Karageorgopoulos DE. Extended spectrum ß-lactamase producing organisms. J Hosp Inf. 2009; 73: 345-354.

PubMed: https://pubmed.ncbi.nlm.nih.gov/19596491/

13. Nathisuwan S, Burgess DS, Lewis JS. Extended Spectrum BLactamases: Epidemiology, Detection, and Treatment. Pharmacother. 2001; 21: 920-928.

PubMed: https://pubmed.ncbi.nlm.nih.gov/11718498/

14. Kumarasamy KK, Toleman MA, Wals TR, Bagaria J, Butt F, et al. Emergence of a new antibiotic resistence mechanism in India, Pakistan and the UK: a molecular, biological, and epidemiological study. Lanc Infect Dis. 2010; 10: 597-602.

PubMed: https://pubmed.ncbi.nlm.nih.gov/20705517/

15. Abbott S. Klebsiella, Enterobacter, Citrobacter, Serratia, Plesiomonas and other Enterobacteriaceae. U: Versalovic J, Carrol KC, Funke G, Jorgensen JH, Landry ML, Warnoc D. Manual of Clinical Mikrobiology 10ed. ASM Press, Washington, DC. 2011; 639-6757.

16. The European Committee on Antimicrobial Susceptibility testing Breakpoint tables for interpretation of MICs and zone diameters (EUCAST). https://www.eucast.org/mic_distributions_and_ecoffs/

17. Clinical and Laboratory Standard Institute. https://clsi.org/about/ blog/how-using-clsi-s-m100-helps-the-fight-against-antimicrobialresistance-1

18. Dortet L, Poirel L, Nordmann P. Rapid Detection of ESBL-Producing Enterobacteriaceae in Blood Cultures. Emer Inf Dis. 2015; 21: 504-507. PubMed: https://pubmed.ncbi.nlm.nih.gov/25695535/

19. Thomson, KS. Controversies about Extended-Spectrum and AMPC Beta- Lactamases. Emerg Infect Dis. 2001: 7: 333-336. PubMed: https://pubmed.ncbi.nlm.nih.gov/11294735/

20. Simmering JE, Tang F, Cavanaugh JE, Polgreen LA, Polgreen PM. The Increase in Hospitalizations for Urinary Tract Infections and the Associated Costs in the United States, 1998-2011. Open Forum Infect Dis. 4: ofw281.

PubMed: https://pubmed.ncbi.nlm.nih.gov/28480273/

21. Zilberberg MD, Shorr AF. Secular trends in gram-negative resistance among urinary tract infection hospitalizations in the United States, 2000-2009. Infect Control Hosp Epidemiol. 2013; 34: 940-946. PubMed: https://pubmed.ncbi.nlm.nih.gov/23917908/

22. Sanchez GV, Master RN, Clark RB, Fyyaz M, Duvvruri P, Ekta G et al. Klebsiella pneumoniae Antimikrobial Drug Resistence. United States, 1998-2010. Emerg Infect Dis. 2013; 19: 133-136. PubMed: https://pubmed.ncbi.nlm.nih.gov/23260464/

23. Naas T, Nordmann P, Vedel G, Poyart C. Plasmid-mediated carbapenem-hydrolyzing beta-lactamase KPC in a Klebsiella pneumoniae isolate from France. Antimicrob Agents Chemother. 2005; 49: 4423-4424.

24. Chakraborty S, Moksina K, Sarker PK, Alam MZ, Karim IA, Abu Sayem SM. Prevalence, antibiotic susceptibility profiles and ESBL production in Klebsiella pneumoniae and Klebsiella oxytoca among hospitalized patient. Periodicum Biologorum. 2016; 118: 53-58.

25. Gniadkowski M. Evolution and epidemiology of extended-spectrum beta-lactamases (ESBLs) and ESBL-producing microorganisms. Clin Microbiol Infect. 2001; 7: 597-608.

PubMed: https://pubmed.ncbi.nlm.nih.gov/11737084/

26. Shehabi AA, Mahafzah A, Baadran I, Qadar FA, Dajani N. High 
incidence of Klebsiella pneumoniae clinical isolates to extendedspectrum B-lactam drugs in intensive care units. Diagn Microbiol Infect Dis. 2000; 36:53-56.

PubMed: https://pubmed.ncbi.nlm.nih.gov/10744368/

27. Tambić Andrašević A. Etiology of urogenital infection. Medicus. 2012; 21: 15-21.

28. Paterson DL, Yu VI. Extended -spectrum beta lactamases: a call for improved detection and control. Clin Infect Dis. 1999; 29: 1419-1422. PubMed: https://pubmed.ncbi.nlm.nih.gov/10585789/

29. Paterson DL, Ko WC, Von Gottberg A, Mohapatra S, Casellas JM, et al. Antibiotic Therapy for Klebsiella pneumoniae Bacteremia: Implications of Production of Extended-Spectrum $\beta$-Lactamases. Clin Infect Dis. 2004; 39: 31-37.

PubMed: https://pubmed.ncbi.nlm.nih.gov/15206050/

30. Sakkas H, Bozidis P, llia A, Mpekoulis G, Papadopoulou C. Antimicrobial Resistance in Bacterial Pathogens and Detection of
Carbapenemases in Klebsiella pneumoniae Isolates from Hospital Wastewater. Antibiotics (Basel). 2019; 8: 85.

31. Grundmann H, Livermore Dm, Giske CG, Canton R, Rossolini GM, et al. Carbapenem-non-suspceptible Enterobacteriaceae in Europe: conclusions from a meeting of national experts. Eurosuveillance. 2010; 15: 22-35.

PubMed: https://pubmed.ncbi.nlm.nih.gov/21144429/

32. Pitout JD, Hanson ND, Church DI, Laupland KB. Population based laboratory survaillance for E. coli producing ESBL: Importance of Community isolates withblaCIX-M genes. Clin Infect Dis. 2004; 38: 1736-1741.

PubMed: https://pubmed.ncbi.nlm.nih.gov/15227620/

33. Shakya P, Shrestha D, Maharjan E, Sharma VK, Paudyal R. ESBL Production Among E. coli and Klebsiella spp. Causing Urinary Tract Infection: A Hospital Based Study. Open Microbiol J. 2017; 11: 23-30. PubMed: https://pubmed.ncbi.nlm.nih.gov/28553414/ 